\author{
Bruno J. Manadas ${ }^{1}$ \\ Konstantinos Vougas ${ }^{2}$ \\ Michael Fountoulakis ${ }^{2}$ \\ Carlos B. Duarte ${ }^{1}$ \\ ${ }^{1}$ Department of Zoology, \\ Center for Neuroscience \\ and Cell Biology, \\ Dept. of Zoology, \\ University of Coimbra, \\ Coimbra, Portugal \\ ${ }^{2}$ Foundation for Biomedical \\ Research of the Academy \\ of Athens, \\ Institute of Biotechnology, \\ Athens, Greece
}

Received June 16, 2005

Revised October 28, 2005

Accepted November 8, 2005
Research Article

\section{Sample sonication after trichloroacetic acid precipitation increases protein recovery from cultured hippocampal neurons, and improves resolution and reproducibility in two-dimensional gel electrophoresis}

\begin{abstract}
Protein precipitation with TCA followed by acetone washing is frequently used to clean samples before 2-DE. However, the difficulty in solubilizing TCA-precipitated proteins causes some variability in 2-D gels and makes it difficult to detect some proteins. In this work we show that sonication of the samples, after TCA precipitation followed by elution in sample buffer, increases total protein recovery, and improves reproducibility and matching ratios between gels when analyzed by specialized software.
\end{abstract}

Keywords: 2-D SDS-PAGE / Hippocampus / Solubilization / Sonication

DOI 10.1002/elps.200500757

\section{Introduction}

The mammalian proteome comprises several million different proteins [1]. Their resolution in 2-D-SDS-PAGE is a great effort requiring fractionation [2] and building of cybergels from zoom IEF gels [3]. Although an improved resolution is achieved with these gels, a higher degree of reproducibility is also required [4] in order to allow a quick matching of the gels by the algorithms available [5] and to speed up the analysis.

Protein samples to be analyzed by 2-DE should be free from salts and other compounds that interfere mainly with IEF, such as nucleic acids and lipids [6]. This may be achieved by various means, including TCA precipitation followed by acetone washing, which was identified as one of the best protocols [7]. The main problem associated with TCA precipitation is the solubilization of the pellet. A chemical approach was previously used to solubilize TCA-precipitated proteins [6]. In SDS-PAGE, proteins are solubilized using a combination of chemical (SDS and DTT) and physical (sample heating) methods.

Correspondence: Professor Carlos B. Duarte, Department of Zoology, University of Coimbra, 3004-517 Coimbra, Portugal E-mail: cbduarte@ci.uc.pt

Fax: $+351-239480208$

Abbreviation: SH, step and hold
However, samples used in 2-D-SDS-PAGE cannot be heated in order to avoid protein modifications induced by urea.

In this work we have tested a combination of methods for sample cleaning and solubilization, using protein precipitation with TCA, followed by sonication in a buffer containing urea, thiourea, CHAPS, and DTT. Our results show that sample sonication after precipitation with TCA increases total protein recovery from cleaned samples and improves the reproducibility between gels.

\section{Materials and methods}

\subsection{Preparation of samples from rat hippocampus}

Adult Wistar rats were sacrificed and the hippocampi were removed. The hippocampi were then sonicated [8, 9] in $50 \mathrm{mM}$ Tris- $\mathrm{HCl} \mathrm{pH} 7.3,1 \mathrm{mM} \mathrm{DTT}$, chymostatin $(1 \mu \mathrm{g} / \mathrm{mL})$, leupeptin $(1 \mu \mathrm{g} / \mathrm{mL})$, antipain $(1 \mu \mathrm{g} / \mathrm{mL})$, pepstatin $A(1 \mu \mathrm{g} / \mathrm{mL})$, and $0.1 \mathrm{mM}$ PMSF, and the resulting suspension was divided into two equal samples. In each case soluble proteins were isolated in the supernatant resulting from ultracentrifugation at $126000 \times g_{\text {av }}$ [9], for $1 \mathrm{~h}$ at $4^{\circ} \mathrm{C}$. Proteins in the pellets (S126) were resuspended in $10 \% \mathrm{w} / \mathrm{v}$ TCA whereas soluble proteins were precipitated by adding $100 \% \mathrm{w} / \mathrm{v}$ TCA, to a final con- 
centration of $10 \%[6,8,9]$. TCA-precipitated fractions were frozen and thawed, in order to improve precipitation, and centrifuged at $14000 \times g_{\max }$ for $15 \mathrm{~min}$ at $4^{\circ} \mathrm{C}$ [6]. Pellets were washed with ice-cold acetone, maintained at $-20^{\circ} \mathrm{C}$, vortexed every $20 \mathrm{~min}$, for $1 \mathrm{~h}$, and centrifuged at $14000 \times g_{\max }$, for $15 \mathrm{~min}$ at $4^{\circ} \mathrm{C}[6,8,9]$. Proteins were solubilized for $2 \mathrm{~h}$ in 2-D-sample buffer (6 M urea (Amersham Biosciences, Carnaxide, Portugal), 1.5 $\mathrm{M}$ thiourea (Sigma, Sintra, Portugal), 3\% CHAPS (Amersham Biosciences USB Chemicals), and $60 \mathrm{mM}$ DTT (Amersham Biosciences)), and sonicated or not, using a $3 \mathrm{~mm}$ stepped microtip (\#630-0422) with a Vibra Cell system (Sonics \& Materials, Danbury, CT). Nonsonicated samples were vortexed for 2 min after disruption of the pellet with a pipette tip. Protein quantification was performed using the 2D-Quant kit (Amersham Biosciences). IPG Buffer (1.5\%, pH 4.5-5.5 or pH 5.5-6.7) was added to the samples prior to IEF (Amersham Biosciences).

\subsection{Hippocampal cultures and radiolabeling experiments}

E18 hippocampal neurons were cultured as previously described [10]. After 7 days in culture, cells were starved from methionine and cysteine for $30 \mathrm{~min}$, and ${ }^{35} \mathrm{~S}$-radiolabeled amino acids (Redivue Pro-mix, $7.5 \mu \mathrm{Ci} / \mathrm{mL}$, Amersham Biosciences) were then added. After $12 \mathrm{~h}$ of incubation the cells were washed with PBS, scrapped, and sonicated in $50 \mathrm{mM}$ Tris- $\mathrm{HCl} \mathrm{pH}$ 7.3, 1 mM DTT, chymostatin $(1 \mu \mathrm{g} / \mathrm{mL})$, leupeptin $(1 \mu \mathrm{g} / \mathrm{mL})$, antipain $(1 \mu \mathrm{g} /$ $\mathrm{mL})$, pepstatin A $(1 \mu \mathrm{g} / \mathrm{mL})$, and $0.1 \mathrm{mM}$ PMSF. Soluble proteins were separated from the remaining protein fraction as described in Section 2.1.

\subsection{Sonication procedure}

Sonication was performed as previously described [9] with slight modifications. Briefly, samples were kept on ice and sonicated in six cycles of $10 \mathrm{~s}$, each consisting of $5 \mathrm{~s}$ sonication followed by a $5 \mathrm{~s}$ break (to keep the samples at low temperature). Each sonication was performed with increasing amplitude, starting from zero, and the amplitude was maintained below 40. Special care was taken to avoid foaming.

\subsection{2-D SDS-PAGE and staining}

Two hundred and fifty micrograms of protein was actively rehydrated for $12 \mathrm{~h}$ at $50 \mathrm{~V}$. IEF was performed according to the manufacturer, with slight modifications: $500 \mathrm{~V}$ $(500 \mathrm{~V} \cdot \mathrm{h}$ step and hold $(\mathrm{SH})), 1000 \mathrm{~V}(1000 \mathrm{~V} \cdot \mathrm{h} \mathrm{SH})$,
$10000 \mathrm{~V}(15000 \mathrm{~V} \cdot \mathrm{h}$ with linear increase), and final focusing at $10000 \mathrm{~V}$ during $14 \mathrm{~h}(\mathrm{SH})$, using a Protean IEF cell (BioRad, Amadora, Portugal). Strips were then equilibrated to SDS $(50 \mathrm{mM}$ Tris- $\mathrm{HCl} \mathrm{pH} 8.8,30 \%$ glycerol, $2 \%$ SDS, and trace amount of bromophenol blue) for $20 \mathrm{~min}$, in the presence of $10 \mathrm{mg} / \mathrm{mL}$ DTT, followed by another $20 \mathrm{~min}$ step in the presence of $25 \mathrm{mg} / \mathrm{mL}$ iodoacetamide. The second dimension was performed in a Protean Plus Dodeca Cell (BioRad), at $3 \mathrm{~W} /$ gel for $30 \mathrm{~min}$, followed by $200 \mathrm{~V}$ for $5 \mathrm{~h}$. All the process was performed at $20^{\circ} \mathrm{C}$. Gels were silver stained as previously described [11], dried, digitalized, and analyzed using PDQuest ${ }^{\mathrm{TM}}$ (BioRad). Gels from radiolabeled samples were dried and placed in contact with a phosphor screen (Amersham Biosciences), and the images were subsequently acquired with a laser scanner $\left(\right.$ Storm $^{\text {TM }}$ - Amersham Biosciences). Spot intensity in silver-stained gels was normalized to the total intensity in valid spots, using PDQuest. This normalization procedure is useful when comparing different gels, wherever possible sources of sample variation cannot be predicted and there is no major difference in total spot number. For autoradiography images, the results were normalized to the total intensity in the gel image. This normalization should be used when there are significant differences between images. Decisions concerning the normalization procedure were taken based on the recommendations of the PDQuest software manual.

\subsection{Protein identification}

For protein ID $500 \mu \mathrm{g}$ of protein were applied to IPG gels for in-gel rehydration, followed by $500 \mu \mathrm{g}$ by cup-loading. IEF and second dimension were performed as described in Section 2.4. Gels were double stained, first with Ruthenium II bathophenanthroline disulfonate (Sigma) [12] and then with homemade colloidal Coomassie (Alfa Aesar, Karlsruhe, Germany) [13]. Spots were picked with the Bruker Spot Picker system, using a spot cutter with $1.5 \mathrm{~mm}$ diameter. Spots were destained (50 mM ammonium bicarbonate, $30 \% \mathrm{ACN}$ ), washed with water, dehydrated using a speedvac, and incubated overnight with $3 \mu \mathrm{L}$ trypsin (Roche, proteomics grade $(10 \mu \mathrm{g} / \mathrm{mL}$ in $10 \mathrm{mM}$ ammonium bicarbonate)). Peptides were then extracted using $10 \mu \mathrm{L}$ of $50 \%$ ACN and $0.1 \%$ TFA. Peptide containing solutions were applied on a 384 steel MALDI target (Bruker) followed by $1 \mu \mathrm{L}$ matrix containing standards $(50 \%$ ACN, $0.1 \%$ TFA, $0.3 \%$ w/v cyano-4hydroxycinnamic acid, $10 \mathrm{pmol} / \mu \mathrm{L}$ bradykinin fragment 1-8 ( $\mathrm{m} / \mathrm{z}$ 904.4861) and $40 \mathrm{pmol} / \mu \mathrm{L}$ adrenocorticotropic hormone fragment 18-39 ( $\mathrm{m} / \mathrm{z}$ 2465.1983)). MALDI Ultraflex from Bruker Daltonics was used for spectra acquisition, with the software controller Bruker Daltonics 
FlexControl Version 2.2. The instrument, operating in Reflector Mode, was calibrated using 400 laser shots accumulated from external standards. Spectra were acquired using a laser power range of $45-65 \%$ and a detection range of $\mathrm{m} / \mathrm{z} 900-3500$. A total of $8 \times 50$-laser shots were accumulated for each spot. The spectra accumulation was done after automatic spectra evaluation, and all spetra analyzed had a resolution higher than 6500 in the range $\mathrm{m} / \mathrm{z}$ 1200-2700. For spectra processing the Bruker Daltonics FlexAnalysis Version 2.2 was used, with SNAP algorithm for detection, Centroid algorithm for editing, and Savitzky Golay algorithm for smoothing. The $\mathrm{S} / \mathrm{N}$ ratio in the spectra analyzed was at least 2.5 , and a quality factor threshold of 50 was selected. Background peak removal was performed based on the contaminant peak list provided by Bruker Daltonics, containing Tryptic autodigest peaks and common keratin fragment peaks. A local MASCOT Server Version 2.0 was used for protein identification. Several identification cycles were performed and the most stringent parameters used were the following: Swiss-Prot/TrEMBL databases, Rattus norvegicus, trypsin with zero missed cleavages, carbamidomethylation and methionine oxidation as fixed and variable modifications, respectively, and 25 ppm error tolerance. Identified proteins had at least four peptides below $10 \mathrm{ppm}$. GO annotations were automatically acquired and manually processed from EBI (http://www.ebi.ac.uk/ EGO).

\section{Results and discussion}

2-D gels have proven to be the best way to resolve thousands of proteins in a single gel $[1,14]$. The technique has been improved over the last decades allowing a broadrange comparison of different proteomes under different experimental conditions $[3,14,15]$. IEF is very sensitive to the nonprotein content of the samples, requiring a clean solution with as little contaminants as possible [6, 14-16]. The increasing number of steps used to prepare these clean samples has resulted in a decrease in protein recovery from consecutive steps [17]. This is the case of TCA precipitation, where solubilization of the pellet represents a critical step. Centrifugation after sample solubilization is a common procedure to remove insoluble material [6, 8, 14]. However, in our experiments we noticed a significant variability in the size of the pellets resulting from the solubilization of proteins precipitated with TCA, even in samples prepared from the same amount of original tissue. This led us to question the solubilization capacity of the buffers generally used in this type of protocol, consisting in 6-8 M urea, 1$2 \mathrm{M}$ thiourea, 2-4\% CHAPS, 50-100 mM DTT, and 0.5$2 \%$ IPG buffer [14, 15, 18-20]. Protein solubilization in
SDS-PAGE is increased by heating the samples in the presence of SDS. However, in 2-D-PAGE the samples have to be kept at a temperature below $30^{\circ} \mathrm{C}$, in order to avoid protein modifications [21, 22]. Therefore, in this case, increased solubilization of the samples has been achieved by extending the incubation period at room temperature and by vortexing [6].

In order to improve protein recovery and to decrease the amount of proteins trapped in the insoluble fraction after TCA precipitation, we have tested the effect of sonication after elution of proteins in 2-D-sample buffer. After precipitation with TCA, the protein pellets obtained from the hippocampal soluble or S126 fractions were sonicated or not in 2-D-sample buffer. Sonication decreased the size of the pellets containing insoluble material (Fig. 1), particularly in the S126 fraction. Quantification of the total protein content in sonicated and nonsonicated S126 fractions showed that this physical treatment increases total protein recovery by $140 \%$, when starting
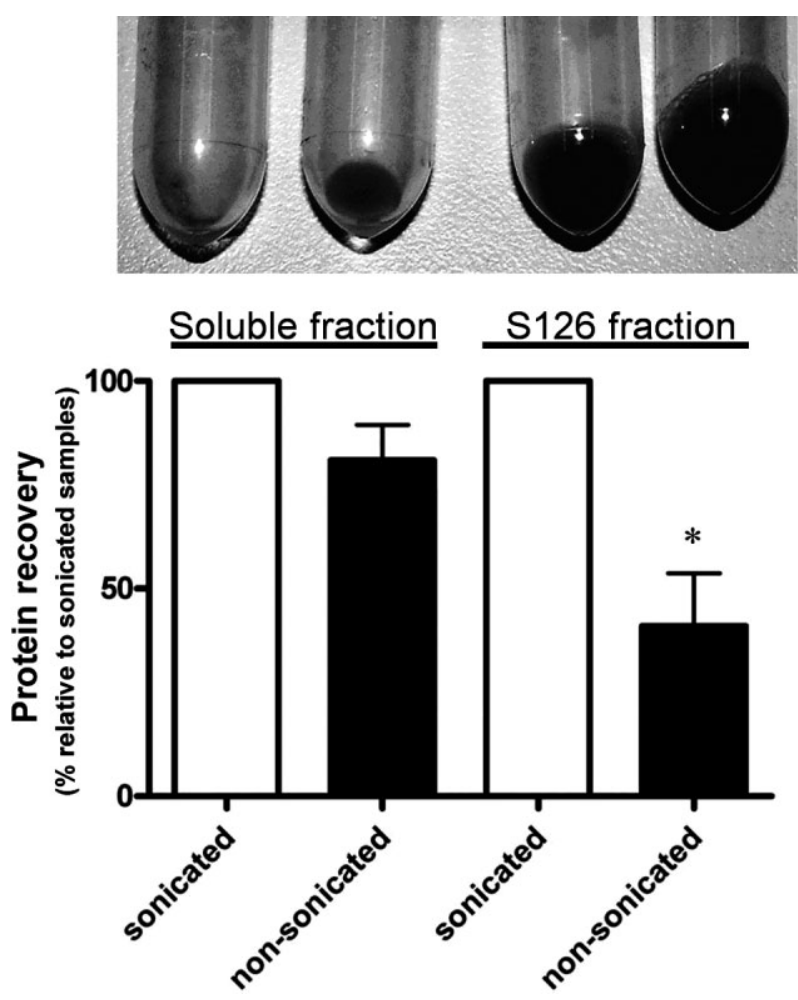

Figure 1. Increase in protein recovery by sonication. Proteins from adult rat hippocampi were separated in soluble and S126 protein fractions by ultracentrifugation. Proteins were solubilized in 2-D sample buffer and either sonicated or vortexed for 2 min. (Top) Pellets obtained after centrifugation to remove nonsoluble material. (Bottom) Protein recovery after quantification using the Amersham's 2-D Quant Kit. Samples $(n=4)$ were analyzed using two-tailed Student's $t$-test with 99\% confidence with $P<0.05\left(^{*}\right)$ (GraphPad Prism, San Diego, CA). 


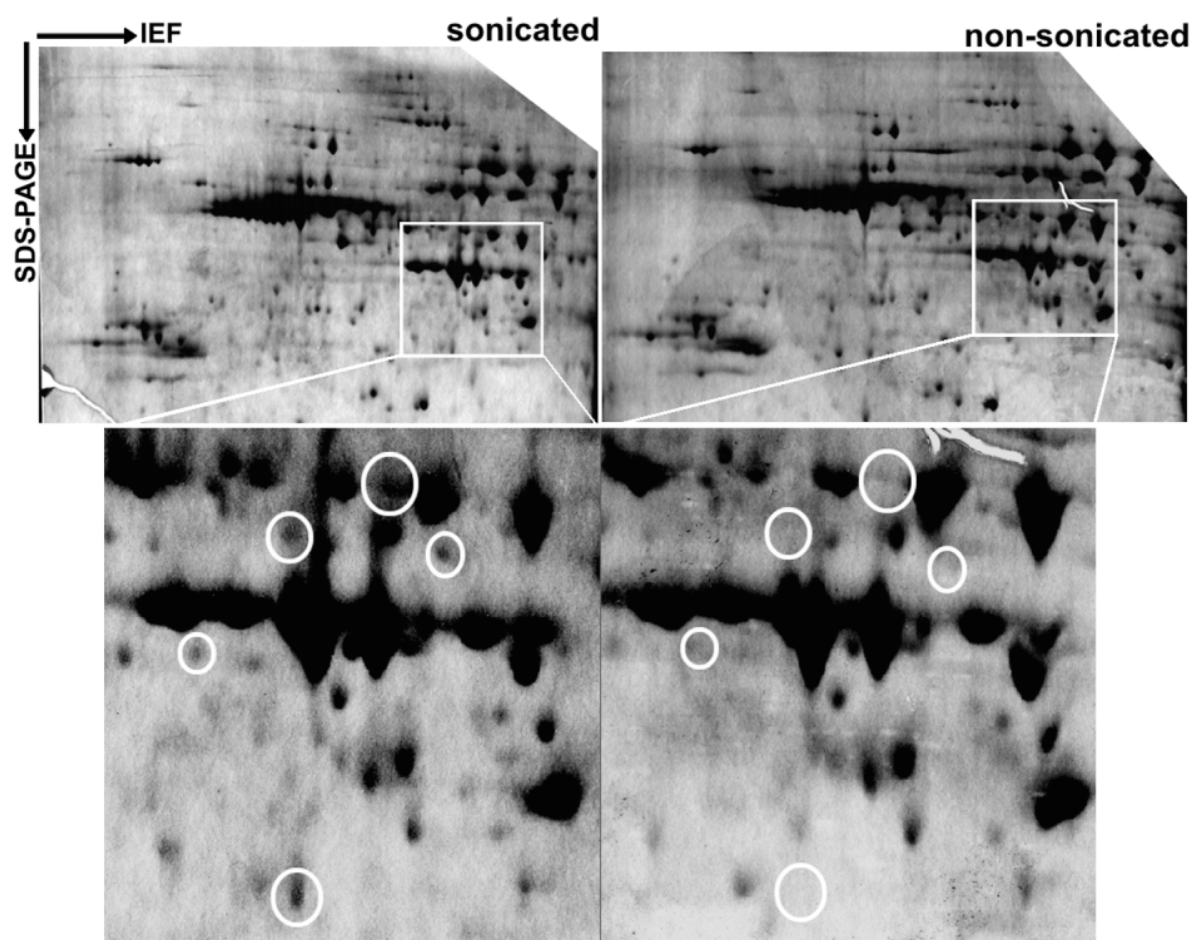

Figure 2. Sonication increases protein solubility and spot resolution. 2-DE of sonicated and nonsonicated S126 fractions prepared from the rat hippocampus. IEF was performed in $24 \mathrm{~cm} \mathrm{pH} \mathrm{4.5-5.5} \mathrm{strips}$ (Amersham Biosciences) and the second dimension was performed in 10\% SDS-PAGE. Circles represent new spots in sonicated samples.

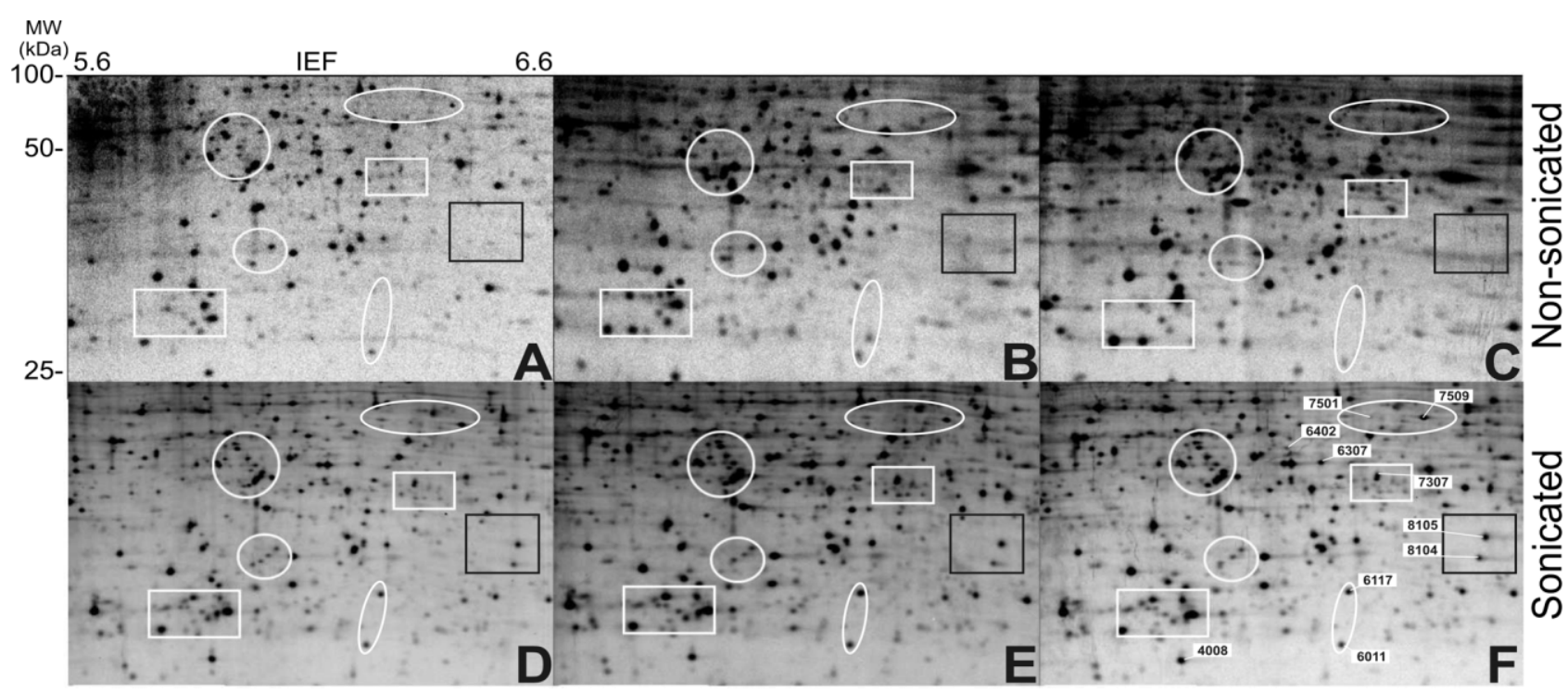

Figure 3. Sonication increases reproducibility and matching ratio. 2-DE of sonicated and nonsonicated S126 fractions prepared from rat primary hippocampal neuron cultures, labeled with ${ }^{35} \mathrm{~S}$-amino acids. IEF was performed in $24 \mathrm{~cm} \mathrm{pH} 5.5-$ 6.7 strips (Amersham Biosciences) and the second dimension was performed in 10\% SDS-PAGE. Three replicate zoomed gels ( $\mathrm{pH}$ 5.6-6.6; $\mathrm{MW}<100 \mathrm{kDa}$ ) are shown for each condition. Top panel: nonsonicated fraction; bottom panel: sonicated samples. Comparison between different gels is shown in Table 2 and protein ID in Table 3.

with the same amount of sample. Although sonication was not so important to increase protein recovery in the soluble fraction, it also reduced protein trapping in the pellet and increased the reproducibility of the gels (data not shown).
The effect of sonication on 2-D-PAGE was investigated in experiments where the same amount of protein, from sonicated and nonsonicated hippocampal S126 fractions, was subjected to IEF and SDS-PAGE (Fig. 2). Although the pattern of both gels was similar, gels from 


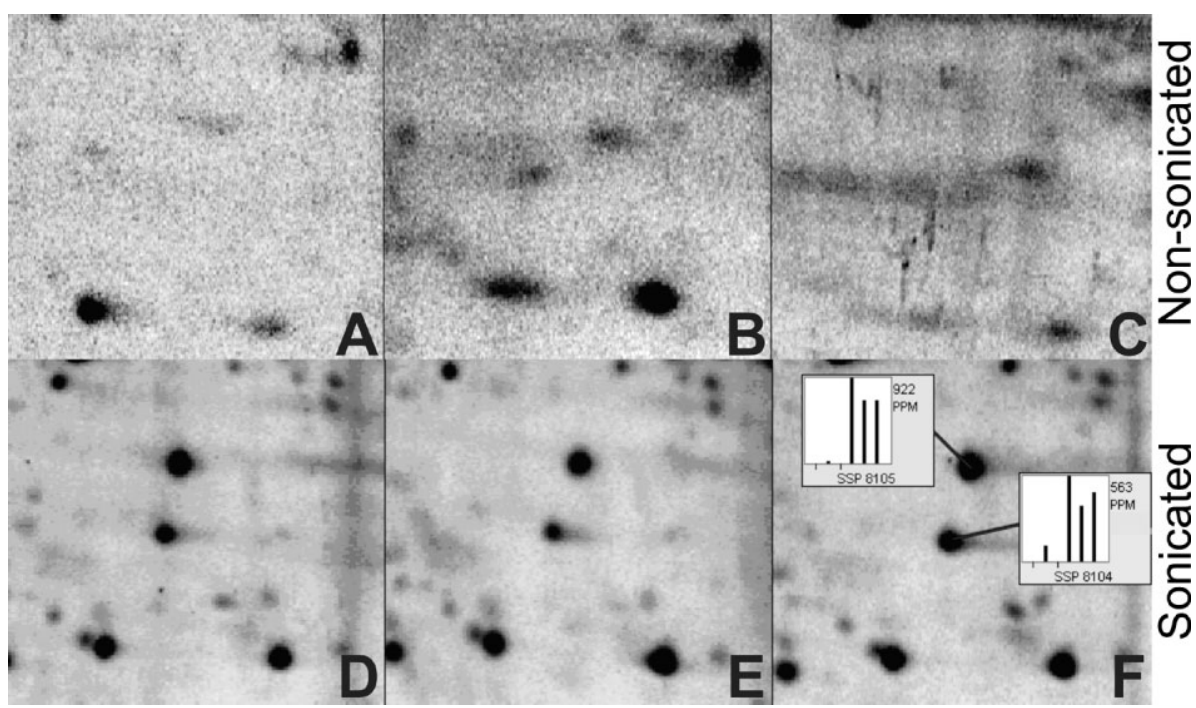

Figure 4. Increase in protein solubility and reproducibility with sonication. PDQuest analysis of the spots contained within the box limited in black in Fig. 3 . Bars represent relative intensity of the spots indicated in the replicate gels $(A-C$, three bars on the left; D-F, three bars on the right). sonicated samples showed several new spots and a different focusing pattern of some spots (e.g., zoomed area in Fig. 2). PDQuest analysis of the gels (Table 1) showed not only an increase in the number of spots in gels obtained from sonicated samples but also an increase in the relative intensity of several spots present in both gels. The increased diversity of spots detected in sonicated samples was associated with a decrease in relative intensity of some abundant proteins, the total amount of protein under the two conditions remaining constant. The magnitude of several spots was increased by more than three-fold, clearly showing an increase in the solubility of these proteins when samples are sonicated.

In order to determine the effect of sonication in the reproducibility of the gels we used extracts prepared from cultured hippocampal neurons incubated with ${ }^{35} \mathrm{~S}$-radio-

Table 1. 2-D gel analysis of the membrane fraction from sonicated and nonsonicated samples. Gels from Fig. 2 were analyzed using PDQuest

\begin{tabular}{lrr}
\hline & $\begin{array}{l}\text { Sonicated } \\
\text { sample }\end{array}$ & $\begin{array}{l}\text { Nonsonicated } \\
\text { sample }\end{array}$ \\
\hline Total number of spots & 173 & 156 \\
New spots & 20 & 3 \\
$\begin{array}{l}\text { Number of spots whose } \\
\text { intensity increased when } \\
\text { compared with the other } \\
\text { condition }\end{array}$ & 104 & 49 \\
$\begin{array}{l}\text { Number of spots whose } \\
\text { intensity increased at least } \\
\text { three times when compared } \\
\text { with the other condition }\end{array}$ & 14 & \\
\end{tabular}

labeled amino acids. Protein spots separated by 2-DSDS-PAGE were detected by autoradiography, which has a much higher sensitivity than colorimetric or fluorescent methods of protein staining [23]. Radiolabeling experiments allow the visualization of low-abundance protein spots and usage of low amounts of protein, thereby decreasing spot streaking. Three replicate gels from nonsonicated and sonicated $\$ 126$ fractions, radiolabeled with ${ }^{35}$ S-amino acids (Fig. 3), were analyzed with PDQuest. After spot detection, gels were automatically matched without manual editing, and the matching ratio was calculated (Table 2). The results show that when each one of the gels prepared from nonsonicated samples was used as a master the matching ratio with the other gels prepared from nonsonicated samples varied between 24 and $36 \%$. Similar matching ratios were calculated in comparison to the gels from sonicated samples (22$28 \%$ ). In contrast, much higher matching ratios were obtained $(61-73 \%)$ when each one of the gels from soni-

Table 2. Matching ratios between gels prepared from nonsonicated and sonicated samples. Gels analyzed (A-F) are those shown in Fig. 3. Each row presents an analysis set (PDQuest) with the score 100 corresponding to the gel used as master

\begin{tabular}{lrrrrrr}
\hline$\%$ & A & B & \multicolumn{1}{c}{ C } & D & \multicolumn{1}{c}{ E } & F \\
\hline A & 100 & 31 & 24 & 24 & 26 & 25 \\
B & 31 & 100 & 27 & 22 & 24 & 24 \\
C & 27 & 36 & 100 & 28 & 26 & 28 \\
D & 30 & 29 & 28 & 100 & 61 & 62 \\
E & 43 & 39 & 40 & 70 & 100 & 73 \\
F & 36 & 40 & 36 & 68 & 68 & 100
\end{tabular}




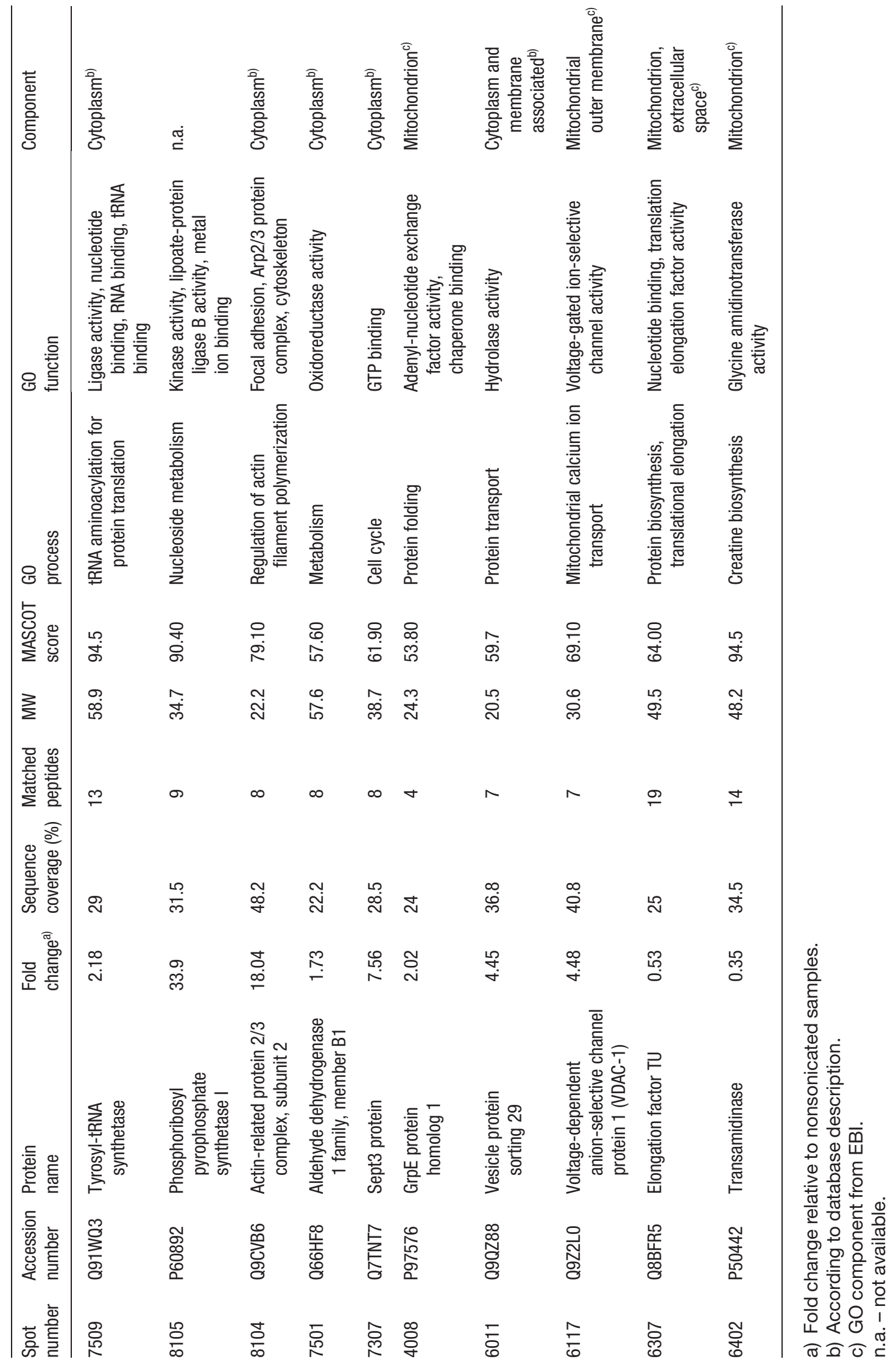


cated samples was used as a master and compared with the others. Interestingly, comparison of these gels with those prepared using nonsonicated samples still gave matching ratios between 28 and $43 \%$. The boxed areas in Fig. 3 clearly show a higher reproducibility in the spots found in gels from sonicated samples than in those from nonsonicated samples. Taken together, the results show that sonication increases reproducibility between gels, thereby decreasing time spent in manual editing.

Some spots whose intensity changed by more than $75 \%$ in the gels prepared from sonicated and nonsonicated samples were identified (numbered spots in Fig. 3 and Table 3; see also Fig. 4). The new spots identified in sonicated samples (Fig. 3) migrated as predicted based on the molecular mass of the proteins, indicating that protein degradation does not account for the differences observed. However, some of the new spots represent low-abundance proteins that could not be identified or even seen with the double staining method used.

\section{Concluding remarks}

Our work shows that the increase in protein recovery from TCA-precipitated proteins, using sonication as a physical approach, in combination with the increase in reproducibility from different gels in different runs, allows a better software analysis. Sample sonication increases the rate of matching, decreases the variability of relative spot intensity between replicate gels, increases the confidence of statistically applied tests, and decreases time spent in software manual editing.

This work was supported by FCT and FEDER, Portugal (Grant POCTI/NSE/46441/2002). Bruno Manadas was supported by FCT, Portugal. We thank Elisabete Carvalho for assistance in the preparation of cell cultures.

\section{References}

[1] Wooley, J. C., Trends Biotechnol. 2002, 20, 316-317.

[2] Fountoulakis, M., Mass Spectrom. Rev. 2004, 23, 231-258.

[3] Oguri, T., Takahata, I., Katsuta, K., Nomura, E. et al., Proteomics 2002, 2, 666-672.

[4] Challapalli, K. K., Zabel, C., Schuchhardt, J., Kaindl, A. M. et al., Electrophoresis 2004, 25, 3040-3047.

[5] Church, S., Biochem. Soc. Trans. 2004, 32, 511-516.

[6] Nandakumar, M. P., Shen, J., Raman, B., Marten, M. R., J. Proteome Res. 2003, 2, 89-93.

[7] Jiang, L., He, L., Fountoulakis, M., J. Chromatogr. A 2004, 1023, 317-320.

[8] Chemale, G., van Rossum, A. J., Jefferies, J. R., Barrett, J. et al., Proteomics 2003, 3, 1633-1636.

[9] Chan, L. L., Lo, S. C., Hodgkiss, I. J., Proteomics 2002, 2, 1169-1186.

[10] Almeida, R. D., Manadas, B. J., Melo, C. V., Gomes, J. R. et al., Cell Death Differ. 2005, 12, 1329-1343.

[11] O'Connell, K. L., Stults, J. T., Electrophoresis 1997, 18, 349359.

[12] Rabilloud, T., Strub, J. M., Luche, S., van Dorsselaer, A. et al., Proteomics 2001, 1, 699-704.

[13] Candiano, G., Bruschi, M., Musante, L., Santucci, L. et al., Electrophoresis 2004, 25, 1327-1333.

[14] Gorg, A., Obermaier, C., Boguth, G., Harder, A. et al., Electrophoresis 2000, 21, 1037-1053.

[15] Molloy, M. P., Anal. Biochem. 2000, 280, 1-10.

[16] Celis, J. E., Gromov, P., Curr. Opin. Biotechnol. 1999, 10, 1621.

[17] Zhou, S., Bailey, M. J., Dunn, M. J., Preedy, V. R. et al., Proteomics 2005, 5, 2739-2747.

[18] Herbert, B., Electrophoresis 1999, 20, 660-663.

[19] Santoni, V., Rabilloud, T., Doumas, P., Rouquie, D. et al., Electrophoresis 1999, 20, 705-711.

[20] Henningsen, R., Gale, B. L., Straub, K. M., DeNagel, D. C., Proteomics 2002, 2, 1479-1488.

[21] Gerstner, A., Csapo, Z., Sasvari-Szekely, M., Guttman, A., Electrophoresis 2000, 21, 834-840.

[22] McCarthy, J., Hopwood, F., Oxley, D., Laver, M. et al., J. Proteome Res., 2003, 2, 239-242.

[23] Gorg, A., Weiss, W., Dunn, M. J., Proteomics 2004, 4, 36653685. 